\title{
Artigos
}

Christiana Cabicieri Proficel

Gabriel Moreira Santos ${ }^{2}$

Nathane Matos Almeida ${ }^{3}$

\section{As brincadeiras entre crianças tupinambá de Olivença: tradições passadas por gerações}

Resumo: As brincadeiras e brinquedos foram e continuam a ser, dispositivos essenciais no processo de formação e preparação de agentes atuantes na ordenação social dos povos indígenas. Calcada em exemplos fornecidos pelos mais velhos, a epistemologia dos povos indígenas necessitava do ávido contato (muitas vezes proporcionado pelas brincadeiras) entre crianças de diferentes idades, adultos e anciãos. Nesta perspectiva, o presente estudo propõe a análise destes dispositivos no contexto da sociedade contemporânea do povo Tupinambá de Olivença (Sul da Bahia), buscando examinar em particular, o importante papel destas atividades lúdico-pedagógicas na transmissão de conhecimentos específicos acerca das relações sociais e com os espaços naturais, e a relevante função de manter e reformular tradições culturais deste grupo étnico. Do ponto de vista teórico e metodológico, fia-se em revisões bibliográficas, relatos de experiência e viagens a campo, onde os pesquisadores fizeram entrevistas e observações participativas em ambientes escolares da comunidade.

Palavras chave: Brincadeiras. Brinquedos. Educação. Indígena. Meio-Ambiente.

\section{The plays between tupinambá children of Olivença: traditions passed by generations}

Abstract: Figured plays and toys were and still are essential devices in the process of development and preparation of active agents in the social ordination of indigenous people. Shaped on examples provided by older people, the epistemology of indigenous people needed avid contact (often provided by plays) among children of different ages, adults and olders. From this standpoint, this paper proposes the analysis of these devices in the context of contemporary society of the Tupinambá people from Olivença (South of Bahia), seeking to analyse in particular the important role of these recreational-educational activities in the transmission of specific knowledge about relations, both social and with the natural environment, and the relevant function to maintain and reshape cultural traditions of this ethnic group. From a theoretical and methodological perspective, this study is based in reviews, experience reports and field trips, where researchers conducted interviews and participant observations in educational environments inside the community.

Keywords: Figured plays. Toys. Education. Indigenous. Environment.

I Professora Doutora do Departamento de Filosofia e Ciências Humanas da UESC.

2 Graduando em História pela Universidade Estadual de Santa Cruz.

3 Graduando em História pela Universidade Estadual de Santa Cruz. 
odemos observar em grande parte das sociedades humanas, uma preocupação diante da manutenção e renovação das suas características culturais, de sua história e do seu modo de vida específico. Para tal fim, os seus agentes sociais precisam se apropriar das características e da dimensão simbólica existente na cultura ao qual estão inseridos. Diante desse processo, os brinquedos e as brincadeiras atuam como importantes dispositivos, propiciando aos agentes durante sua infância e de forma lúdica, as características culturais necessárias para o desenvolvimento e manutenção desta sociedade específica.

Neste vetor, o presente trabalho, fruto das observações participativas durante o projeto de iniciação à docência intitulado como, "O meio ambiente como tema transversal - o desafio das escolas indígenas", realizada pela Universidade Estadual de Santa Cruz (UESC), nos anos de 2012 e 2013 em parceria com a escola e creche indígena Katuana, uma das 19 instituições nucleadas da Escola Estadual Indígena Tupinambá de Olivença (EEITO), localizada no sul do estado da Bahia, propõe a análise destes dispositivos no contexto da sociedade contemporânea do povo Tupinambá de Olivença, buscando examinar, em particular, o importante papel destas atividades lúdicopedagógicas, na transmissão de conhecimentos específicos acerca das relações socioambientais; e a relevante função preservadora e ressignificativa das tradições culturais deste grupo étnico. Do ponto de vista teórico e metodológico, a pesquisa foi alicerçada sob o trabalho de observação colaborativa junto às atividades pedagógicas efetuadas pelos professores e estudantes em sala de aula e nos ambientes naturais localizados no entorno da escola, e norteada à luz da interdisciplinaridade, pois ao buscar referenciais nas áreas da Psicologia, História e Antropologia podemos analisar os pontos supracitados a partir de múltiplas perspectivas. Revisões bibliográficas, relatos de experiência e entrevistas, também fazem parte do nosso aporte teórico. 
Por muito tempo no Brasil, segundo a discussão proposta por John Monteiro (2001) em sua tese Tupis, Tapuias e Historiadores ${ }^{4}$, a historiografia enxergava os índios a partir de duas perspectivas. A primeira, encabeçada por Varnhagen ${ }^{5}$, desconsiderava o índio como sujeito histórico, enquanto a segunda, com o ar fortemente pessimista de von Martius ${ }^{6}$, entendia que os povos originários estavam à beira da total extinção, resultado do processo de inserção e "civilização" dos povos indígenas na sociedade não-indígena. Esta visão dualizada e simplista do "índio aculturado" ou do "índio puro"» (ALMEIDA, 2003) construída no século XIX, se manteve cristalizada no imaginário nacional e em nossa historiografia até a década de 1970. Com o passar dos anos este quadro começou a ser alterado a partir de trabalhos interdisciplinares envolvendo os esforços de historiadores, antropólogos, linguistas e arqueólogos, permitindo assim, segundo John Monteiro (2001), a elaboração de uma nova história indígena e consequentemente, uma nova metodologia para trabalhar este objeto de estudo.

A necessidade em reformular teorias, conceitos e ferramentas metodológicas, se fez presente diante da demanda de novas análises e reflexões sobre a historicidade desses grupos étnicos. Os antropólogos direcionaram seus interesses para o processo de mudança social, entendendo que o seu objeto de estudo não é estático nem imutável. Por sua vez, os historiadores passaram a reconhecer as crenças e comportamentos no cotidiano de homens e mulheres comuns, antes considerados irrelevantes. É imprescindível salientar a contribuição do historiador Edward Palmer Thompson, que ressaltou a importância da historicidade da cultura. Em outras palavras, a cultura para Thompson ${ }^{9}$ (1987), é um produto histórico, dinâmico e flexível que deve ser apreendido a partir das experiências vivenciadas por homens e mulheres. Em vistas destes novos paradigmas teóricos e conceituais, podemos evidenciar nos processos históricos a complexa metamorfose cultural suscitada pelos encontros entre índios e não-índios.

Alicerçados nesta discursão, sabemos que os Tupinambá (grupo étnico majoritariamente ocupante da costa e possuidores de uma mesma língua, o Tupi) atuaram de forma significativa na exploração e conquista do litoral brasileiro pelos europeus. Conforme a Conferência Nacional dos Bispos do Brasil - CNBB- (2003), eles ocupavam um extenso território a beira mar, perpassando as regiões dos atuais estados da Bahia, São Paulo e Rio de Janeiro. Suas aldeias eram economicamente

4 MONTEIRO, John. Tupis, Tapuias e historiadores: Estudos de história indígena e do indigenismo. Tese (Livre Docência). Campinas: UNICAMP, 200I

5 Francisco Adolfo de Varnhagen, o visconde de Porto Seguro, foi um militar, diplomata e historiador brasileiro. Nasceu em São João de Ipanema (atual Sorocaba), São Paulo, em

17 de Fevereiro de 1816, porém viveu toda sua vida em Lisboa, Portugal.

6 Carl Friedrich Philipp von Martius (1 794 à 1868), foi um médico, botânico, antropólogo e um dos mais importantes pesquisadores alemães que estudaram o Brasil,

especialmente a região da Amazônia.

7 Termo utilizado para definir o grupo indígena que entrou em contato com uma cultura estrangeira.

8 Definição para o grupo indígena que ainda não teria contato com a cultura europeia.

9 THOMPSON, E. P. A formação da classe operária inglesa. Rio de Janeiro: Paz e Terra, 1987 
autossuficientes e possuíam em torno de 300 a 1000 membros, organizados socialmente a partir do papel em que cada integrante exercia dentro da lógica do trabalho coletivo.

Durante o século XVI, os cronistas portugueses relataram em seus tratados descritivos a acentuada disparidade cultural entre os Tupinambá e os europeus, ressaltando o distinto modo de vida dos povos originários, a sua organização política, as práticas de batalha, sua maneira de educar assistêmica, sua cosmogonia e formas de dividir o tempo, bem como a manutenção de suas tradições através da oralidade e dos rituais. Todavia, os portugueses visando lograr o projeto colonial, buscaram de muitas formas superar estas disparidades.

Dando seguimento ao processo de colonização do novo território, os portugueses utilizaram inúmeras estratégias para garantir e tirar proveito da nova terra "descoberta". De acordo com MONTEIRO (1994), na primeira metade do século XVI, a participação indígena foi crucial para a sobrevivência dos estrangeiros na nova colônia. As relações euroindígenas eram permeadas por alianças e conflitos, onde os portugueses ao perceberem a importância da guerra na dinâmica social indígena, optaram por se engajar neste processo beligerante visando angariar mão-de-obra escrava resultante destas batalhas.

Em paralelo, alguns povos indígenas como os Tupinambá, reconheceram o poder bélico dos estrangeiros e com estes firmaram alianças com o objetivo de derrotar os seus inimigos seculares, neste caso os Tupiniquim. Entretanto, estas relações se mostraram bastante nocivas para os povos originários, visto que além das epidemias causadoras de verdadeiros genocídios, o projeto colonial demandava cada vez mais mão-de-obra e gêneros alimentícios primários. Diante dessa demanda, os colonos atuaram de duas formas, a princípio tentaram por meio do escambo, onde

(...) os portugueses ofereciam ferramentas, espelhos e bugigangas aos chefes indígenas na expectativa que estes organizassem mutirões para as lavouras europeias. Embora útil na derrubada das matas para o preparo de roças, esta forma mostrou-se inadequada, esbarrando na aparente inconstância dos índios (Monteiro, 1994, p.30).

$\mathrm{Na}$ segunda estratégia de recrutamento de mão-de-obra, os portugueses buscavam ensejar a guerra indígena objetivando a produção de prisioneiros de guerra, que em vez de sacrificados e devorados, seriam negociados como escravos. Todavia, nenhuma das medidas surtiu muito efeito, devido, principalmente, pela recusa dos índios em negociar seus presos de guerra e futuros sacrificados no ritual antropofágico.

Frente a este entrave, estava claro para os colonos, que o futuro do projeto colonial dependia de mão-de-obra e da estrutura alimentícia até então fornecidas pelos indígenas, e para tal fim eles deveriam intervir nos alicerces culturais e ideológicos destes povos. Desta forma, 
(...) ficava mais claro para os portugueses que a transformação do prisioneiro em escravo, através da manipulação da guerra, envolvia antes a redefinição ritual e social do sacrifício humano. Apesar de a maior parte dos grupos locais lutar pela preservação de suas tradições, as relações euroindígenas acabaram provocando mudanças significativas. Alguns grupos tupiniquim, por exemplo, sobretudo após a chegada dos jesuítas, abandonaram a antropofagia e passaram a dar um enterro cristão aos inimigos mortos (Monteiro, 1994, p. 33).

Ademais, era notório para as autoridades portuguesas que a insubordinação e rebeldia indígena estavam ligadas às desastrosas ações europeias, em medida que a exploração da mão-deobra nativa progredia, a resistência armada era recíproca, culminando em um declínio demográfico dos nativos. A partir destas problemáticas, a Coroa lusitana se caracteriza de fato como agente social e passa a intervir na colônia, criando legislações ${ }^{10}$ e dando passos iniciais para a construção das primeiras políticas indigenistas na América Portuguesa.

Os primeiros passos desta recém criada política indigenista, materializaram-se na figura das missões e aldeamentos jesuíticos. Para a Coroa lusitana, esta alternativa seria a solução para organizar o espinhoso caso da escravidão indígena, visto que essa nova ferramenta passou a ser utilizada pelos povos estrangeiros para garantir seus objetivos.

Os aldeamentos jesuíticos, gerenciados por membros da Companhia de Jesus, ao impôr a sua cultura constituíam-se como espaços de desarticulação ideológica frente às nações indígenas. Para facilitar este processo, os jesuítas buscavam "reeducá-los" sob a égide da doutrina cristã, utilizandose das crenças e da linguagem nativa para a criação de mediações religiosas visando facilitar o processo de catequização.

\begin{abstract}
(...) estas missões foram caracterizadas pela mistura de povos e culturas, o que, por um lado, contribuía para a estratégia jesuítica de homogeneização, porém por outro, desarticulava a sociedade indígena. De fato, no seu esforço em transformar os aldeamentos em mecanismos ideais para manipulação e controle dos povos indígenas, os jesuítas buscavam, de forma meticulosa, demonstrar os elementos fundamentais da organização social e cultural de diversos grupos locais, substituindo-os por um modelo radicalmente divergente (Monteiro, 1994, p. 47).
\end{abstract}

Estas práticas, sob a perspectiva jesuítica, garantiam a mão-de-obra para extração de madeira, abertura de estradas e clareiras, segurança do território contra outros índios e outros povos estrangeiros. Para os outros colonizadores (agentes da coroa portuguesa que não faziam parte da Companhia de Jesus), estas práticas caracterizavam-se em uma usurpação dos bens da coroa portuguesa e monopólio da mão-de-obra gentílica. No entanto, para os grupos indígenas, era uma

10 Lei de 20 de março de 1570, buscava regulamentar, mas não proibir o cativeiro indígena e delineava os meios legítimos para adquirir cativos, sendo estes por meio da "guerra justa" devidamente autorizada pelo rei ou governador, ou para "salvar" os índios que estavam condenados à morte em rituais antropofágicos. 
forma de viver diante desta nova realidade, em contato com homens de cultura tão díspar e opressora, com poder bélico acentuado e idiossincrasias diversas. Em suma, os aldeamentos não eram simples espaços de desagregação da cultura indígena e imposição da cultura ocidental ou da religião cristã, mas, espaços de negociação e conflitos entre missionários, colonos, e os índios aldeados.

\title{
Vestígios no Tempo: O Povo Tupinambá de Olivença
}

No final do século XVII, foi fundado ao sul da capitania de São Jorge dos Ilhéus, o aldeamento de Nossa Senhora da Escada (LEITE, 1945), um espaço de constante luta, resistência e negociações entre os agentes sociais comuns aos aldeamentos. Posteriormente, na segunda metade do século XVIII,

\begin{abstract}
A vila Nova de Olivença foi criada por Carta Régia em 1758, com sede administrativa instalada na Igreja de Nossa Senhora da Escada. A vila foi caracterizada pelas autoridades provinciais e locais como indígena, justificada pela antiga condição de aldeamento e pelo fato de a maioria dos moradores serem descendentes dos indígenas (Marcis, 2004, p. 78).
\end{abstract}

Contudo, o longo e intermitente processo de expropriação cultural e territorial caracterizada por revoltas e supressão de identidades étnicas perdurou até o ano de 2002, quando a FUNAI (Fundação Nacional do Índio) reconheceu a existência dos Tupinambá de Olivença ${ }^{11}$ - grupo indígena anteriormente identificados como "caboclos", visto que o conflito de terras na região gerava o risco de morte ao se auto-afirmar indígena - e deu início à demarcação de terras (questão não resolvida e que ainda hoje, engendra conflitos entre índios e fazendeiros). Devido aos conflitos de terra, nos deparamos com problemas sociais que afetam toda e qualquer comunidade rural, além da visão estereotipada do índio ainda existente no imaginário local o que resulta em uma negação para com a existência dos Tupinambá. Estes aspectos da dinâmica social acabam por dificultar a consolidação de políticas públicas, inclusive no âmbito da educação escolar indígena nesta comunidade. Após a constituição de 1988 foi assegurado o direito da educação escolar indígena, regulamentada pela Resolução no 3 de 1999 do Conselho Nacional de Educação (CNE, 1999).

Art. $1^{\circ}$ Estabelecer, no âmbito da educação básica, a estrutura e o funcionamento das Escolas Indígenas, reconhecendo-lhes a condição de escolas com normas e ordenamento jurídico próprios, e fixando as diretrizes curriculares do ensino intercultural e bilíngüe, visando à valorização plena das culturas dos povos indígenas e à afirmação e manutenção de sua diversidade étnica.

\footnotetext{
II Atualmente, de acordo com a Fundação Nacional da Saúde - FUNASA - (2010), existem cerca de 4.664 índios da etnia Tupinambá de Olivença. Divididos na aldeia mãe
} em Olivença e em outras 23 comunidades. Sua maioria está situada no município de llhéus, e os demais estão localizados nos municípios de Una e Buerarema. 
A partir daí, foram criadas escolas focadas no resgate e preservação das crenças, costumes e cultura desses povos, atuando como importante entidade social, contribuindo para o bem viver de cada comunidade indígena e agindo de forma a assegurar seus territórios.

\section{O Papel da Educação e das Brincadeiras na Sociedade Tupinambá de Ontem e Hoje}

Podemos observar em grande parte das sociedades humanas, uma preocupação diante da manutenção e renovação das suas características culturais, de sua história e do seu modo de vida específico. Para tal fim, os próprios agentes sociais compreendem que a busca contínua por formas e métodos de modelar a personalidade, a vontade e ações de seus personagens constituem uma atitude essencial para garantir a existência deste mesmo grupo em todos os seus aspectos. De acordo com Florestan Fernandes ${ }^{12}$, a educação caracteriza-se como importante dispositivo social durante o processo de "modelagem", atingindo e norteando a consciência e a prática dos indivíduos para o mesmo sentido.

Em sua obra Notas sobre a educação na sociedade Tupinambá ${ }^{13}$ (1975), produzida a partir dos relatos de cronistas que visitaram a antiga América Portuguesa, atual Brasil, Florestan Fernandes versa sobre as especificidades do processo educacional do povo Tupinambá, grupo étnico que viveu e ainda vive em alguns pontos do litoral brasileiro. Utilizando o método sociológico conhecido como funcionalismo, o autor analisa a educação na sociedade Tupinambá por um viés estrutural e dinâmico, onde a formação societária "tradicionalista", "sagrada" e "fechada" atua de forma a integrar e organizar seus membros, enxergando a educação como mecanismo psicossocial e sociocultural que assegura a herança cultural através do enraizamento de um padrão de equilíbrio dinâmico do sistema societário.

Neste plano conceitual, quando falamos em educação como mecanismo psicossocial, precisamos ter em vista, que a sociedade Tupinambá do século XVI constituída por métodos de preservação social baseados na uniformidade cotidiana do coletivo ou do todo não sufocava o sujeito em suas atitudes dissociativas do grupo, pelo contrário, era permitido e exigido um comportamento variável. Portanto, este mecanismo agia de forma a garantir o bem estar pessoal do indivíduo, bem como do coletivo.

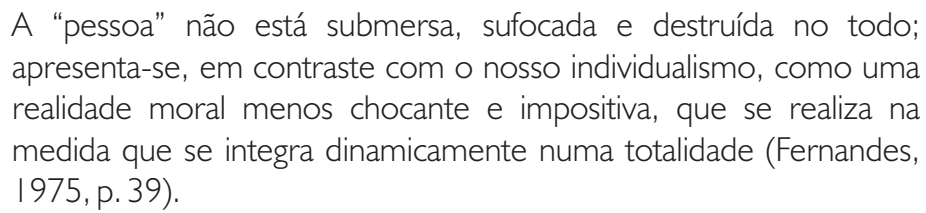
apresenta-se, em contraste com o nosso individualismo, como uma realidade moral menos chocante e impositiva, que se realiza na medida que se integra dinamicamente numa totalidade (Fernandes, 1975, p. 39).

12 Importante intelectual brasileiro do século XX. Sociólogo e professor universitário com mais de cinquenta obras publicadas, transformou o pensamento social do país e estabeleceu um novo estilo de investigação sociológica caracterizado pelo rigor analítico e crítico, e um novo padrão de atuação intelectual.

13 FERNANDES, Florestan. "Notas sobre a educação na sociedade tupinambá". In: FERNANDES, F. A investigação etnológica no Brasil e outros ensaios. Petrópolis: Vozes, 1975, pp. 33-83. 
Em paralelo, a educação como mecanismo sociocultural configura-se como um elo entre a sociedade, seus componentes e a cultura. Ela funciona neste processo, como "máquina” geradora de membros capacitados em transmitir tradições culturais para os mais jovens, fazendo com que seus conhecimentos, valores e formas de viver não se percam no tempo. Além disso, esta máquina é autoreguladora, pois em uma sociedade alicerçada na prática como forma de ensinar, os agentes precisam seguir à risca as condutas tradicionais e os costumes sagrados, visto que ele próprio - o agente-se constitui como exemplo para os demais.

\section{(...) ninguém se eximia do dever que convertia a própria ação em modelo a ser imitado. Em consequência, os adultos em geral e os velhos em particular recebiam essa sobrecarga de uma maneira que não os poupava, já que tinham de "dar exemplo" e, por isso, estavam naturalmente compelidos a agir como autênticos "mestres". $\bigcirc$ seu comportamento manifesto tinha de refletir, tanto quanto as suas palavras, o sentido prático das tradições (...)(Fernandes, 1975, p. 48).}

Para além dos mecanismos supracitados, a educação Tupinambá é constituída por complexas particularidades, solapando o discurso etnocentrista de alguns teóricos que partem de um prisma genérico e estereotipado e descrevem esta organização societária e seus dispositivos como simples padronizadores de comportamentos baseada em mera reprodução de ações entre os imaturos (jovens) e os mais velhos (FERNANDES, 1975). Cada sistema social utiliza suas energias intelectuais dentro dos limites de seu horizonte cultural e de suas necessidades estruturais. Não podemos mensurar ou classificar esta forma de organização a partir de uma escala civilizatória ou primitivista, muito menos quando a análise não adentra os limites mais profundos da dinâmica organizacional. Dito isto e tomando direção contrária à este prisma, evidenciaremos importantes traços e funções da educação na sociedade Tupinambá do século XVI, paralelamente às características e o papel da educação e das brincadeiras na sociedade Tupinambá do século XXI.

Primeiramente, este paralelo será traçado a partir da obra Notas sobre a Educação na Sociedade Tupinambá (1975), do sociólogo Florestan Fernandes e a partir de observações participativas em ambientes escolares e entrevistas com integrantes do povo Tupinambá de Olivença. De acordo com Florestan (1975), a educação possuía um sentido comunitário, o acesso ao conhecimento básico era democrático, a transmissão de cultura se fazia através do intercambio cotidiano, contatos pessoais face a face, sem recursos ou técnicas de educação sistemática ou pedagógicas, mas, por intermédio da oralidade e das próprias circunstâncias ensejadas pela rotina de vida diária; todos podiam aprender algo em qualquer tipo de relação social, o que transformava qualquer sujeito em agente de educação, prospectando as funções de mestre e aprendiz em qualquer nível social, reservando justa importância para os mais velhos, que carregavam a função de atualizar a 
memória coletiva e encontrar nas tradições as respostas à novos anseios. Todavia, ainda que o processo de transmissão de conhecimento perpassasse a todos os membros e em qualquer momento de sua vida, este sistema era constituído por certas especificidades balizadoras: a idade, o sexo, o "sagrado" e os limites elencados pela composição das "parentelas", se instituíam como crivo - ainda que pouco rígido - nesta lógica.

Diante desta estrutura, devemos sublinhar acentuadamente, o valor das tradições e seu caráter dinâmico e adaptativo. As tradições delineavam os níveis de importância moral das ações, o que consequentemente suscitava a busca por equiparação das ações pessoais a estas atitudes tradicionais. Em outras palavras, em uma sociedade onde o "aprender fazendo" se constitui como um axioma educacional, as tradições davam significados valorativos às maneiras de agir, que por sua vez, fomentavam a busca pessoal para manter-se nestes parâmetros. Grande parte das atitudes na sociedade Tupinambá eram compostas por todo um conjunto de significados e funcionalidades. Ainda que estes significados não estivessem ao alcance dos imaturos, fazia-se necessário o aprendizado prático pelos mesmos, pois o entendimento dos valores culturais viria com a maturidade e convivência.

\section{(...) os adultos envolviam os imaturos em suas atividades ou estimulavam reprodução de situações análogas entre as crianças, promovendo dessa forma sua iniciação antecipada nas atividades, nos comportamentos e nos valores incorporados à herança-cultural. (Fernandes, 1975, p. 68).}

Isto posto, ao traçarmos um paralelo entre nossa fonte bibliográfica e os resultados de nossa ida à campo, identificamos situações congêneres em uma de nossas entrevistas. Nossa entrevistada de nome Jacira (nome fictício), com idade próxima aos 40 anos, nos forneceu esta entrevista no dia 24/07/2013, ela nos relatou sobre brincadeiras de sua infância envolvendo meninos e meninas, cada um com seu dever. Os garotos responsáveis por ir à mata cortar madeira, e as garotas incumbidas por cortarem e transportarem a palha; ao final, construía-se uma miniatura de casa de taipa (moradia construída com técnica vernacular utilizando argila).

Jacira: Fazíamos casinhas de palhas ${ }^{14}$, os meninos responsáveis por cortar as madeiras e as meninas catarem as palhas. Depoisjuntávamos, todosjunto, o barro, as madeira e as palhas, e montávamos as paredes e o teto.

\section{Pesquisadores: Alguma brincadeira sofria intervenção de seuspais?}

Jacira: Sim, além desta da casinha, tínhamos as canções e brincadeiras de roda nos dias de lua cheia.

Pesquisadores: Como eram estas canções e brincadeiras nos dias de lua cheia?

Jacira: Cantávamos para Jacy ${ }^{15}$ em tupi (...) esta canção é umas das poucas cantadas em nossa língua mãe.

\footnotetext{
14 Sabemos que as moradias do povo Tupinambá de Olivença obedecem à estas características, e de acordo com o relato de Jacira, podemos inferir que determinadas brincadeiras eram encarregadas de introduzir a prática de funções adultas ainda no contexto infantil.

I5 Jacy ae aende jacy (...) Mba epe moindy iande taba (...)Tupã our tym. Isape iandé taba. Tradução: Jacy é a nossa lua (...) Que clareia a nossa aldeia (...)Tupã venha arramiá, iluminar a nossa aldeia.
} 
Jacira: Tínhamos o costume de brincar de roda durante a lua cheia, onde recontávamos as histórias e poesias que ouviamos de nossos pais. Quando não era lua cheia, ficávamos dentro de casa tomando "giróba" [bebida feita de mandioca] e ouvindo histórias contadas pelos pais, sobre onça, cobra pico de jaca e outros animais da mata. Nossos pais sempre nestas histórias e poesias nos contavam como proteger a roça destes bichos e também de nos proteger... se sentíssemos o cheiro de cabaça [fruta da região] tínhamos de sair ligeiro... era sinal de onça. Já com a cobra pico de jaca... era o cheiro da jaca [fruta da região] dai que vem o nome do bicho, ela gosta de ficarperto dessespé de planta(sic).

Estas brincadeiras de roda, contação e recontação de histórias transmitiam conhecimentos específicos de sua realidade, contribuindo para preservação da memória coletiva e formação de uma consciência ecológica, pois o respeito à natureza e seus respectivos elementos se mostra transversal em praticamente toda a fala da entrevistada. Tendo a oralidade como principal instrumento de transmissão, estas atividades funcionavam, também, como mecanismo sociocultural, cuja as tradições, costumes e herança cultural eram passados para os mais novos por meio das interações cotidianas com os mais velhos de uma forma lúdica e divertida.

Outras formas de brincadeiras foram relatadas, como a construção de pequenos arcos e flechas compatíveis à sua estatura, confecção de cocares, bonecas feitas a partir do sabugo de milho e folhas de bananeira. Diferente da construção das casinhas, segundo nossa leitura, estas brincadeiras não possuíam uma funcionalidade direcionada para o trabalho futuro, visto que arcos e flechas não eram mais utilizados na prática da caça ou da pesca. No entanto, uma brincadeira nos chamou bastante atenção. De acordo com Jacira, a brincadeira de "pular a fogueira" nas festas de Junho, detinha grande importância na conservação do convívio comunitário e familiar, visto que os integrantes do grupo que estivessem brigados deveriam pular a fogueira de mãos dadas sussurrando palavras de união (tais palavras não foram reveladas), em seguida, as desavenças seriam "queimadas" no fogo e os participantes passariam a se considerar "comadres" ou "compadres", mantendo esses laços de fraternidade até sua vida adulta. Esta brincadeira ou rito, possivelmente é fruto de trocas interculturais entre os povos indígenas e os colonizadores, haja vista relatos e descrições desta situação em obras sobre a história social europeia que abordam a idade média (KISHIMOTO, 1993). Todavia, compreendemos o processo de ressignificação cultural adotado pelos povos originários, consistindo em reformular determinados costumes estrangeiros de acordo com sua realidade e cultura.

Isto posto, podemos inferir que as práticas educacionais desenvolvidas assumiam um caráter assistêmico, levando em consideração a ausência de momentos pedagógicos específicos para educar ou transmitir algum tipo de conhecimento. Situação totalmente condizente aos parâmetros da educação indígena praticada dentro da aldeia, junto com seus pais, irmãos e lideranças, e distante dos 
moldes institucionalizados da educação escolar indígena, caracterizada por reproduzir parcialmente os modelos de ensinar dos colonizadores.

Não podemos perder de nosso horizonte, o caráter autônomo das brincadeiras infantis livre de qualquer intervenção adulta. Porém, algumas brincadeiras transparecem a forma tradicional de educar do povo Tupinambá, onde as atividades lúdicas direcionadas por sujeitos mais velhos, tem o papel de iniciar os novos agentes sociais em práticas manuais, que futuramente serão exercidas com significativa importância para sua vida adulta, e consequentemente, atuarão como alicerces no processo construtivo de significados e costumes culturais norteadores deste povo. Não obstante, outros aspectos da funcionalidade da educação e das brincadeiras gravitam em torno desta análise. Por exemplo, quando o sujeito deste grupo se encontra em determinada idade e atinge certas posições dentro da "malha" social, ele passa a ter contato com saberes abstratos. Quando mais jovem, o mesmo sujeito educado empiricamente, reproduzindo em seu contexto infantil e sob o formato de algumas brincadeiras a realidade dos adultos, entrará em contato com os saberes filosóficos de sua cultura, compreenderá dentre outras questões abstratas, a cosmogonia de seu povo. Estes saberes intangíveis e de viés filosófico, assumem um importante papel na construção do ser em face a seu meio físico e social.

Isto é, a noção de parentesco, territorialidade e o sentimento de pertença para com os espaços naturais, tanto do ponto de vista material (a natureza como espaço de existência, fonte de alimento e matéria prima para construção de moradia, utensílios domésticos e ferramentas) quanto no sentido espiritual (a natureza como lugar dos "encantados" e seres etéreos mantenedores e protetores do mundo), são forjados neste momento da vida, que por sua vez, preenche uma importante etapa no dinâmico ciclo da organização societária Tupinambá. Em resumo, estamos

literalmente, diante de uma situação histórico-cultural na qual a educação forma o homem sob todos os aspectos e em todas as direções possíveis (Fernandes, 1975, p. 85).

\section{Atividades Lúdico-Pedagógicas em Espaços Naturais e Escolares}

A Escola Estadual Indígena Tupinambá de Olivença (EEITO) situada em Sapucaeira distrito de Ilhéus no Sul da Bahia, procura proporcionar um espaço de resgate da memória coletiva, de traços culturais que tem sido apagados com o tempo, e de manter viva a interação da criança com o ambiente natural, característica fundamental dessa cultura ${ }^{16}$. Ao contrário das escolas não-indígenas, 
onde as crianças são obrigadas a se manterem presas em lugares fechados, rodeados de paredes, quase sempre interagindo com brinquedos industrializados, integrando-as desde cedo ao mundo do consumo, essas crianças indígenas são frequentemente levadas a diferentes espaços, como a praia, jardins, rios, onde brincam livremente com a grama, com a terra, com a água, nadam, mergulham no mar, correm, sobem árvores, tendo contato intenso com o meio natural, e principalmente aprendendo a preservá-lo. Diante do desequilíbrio ambiental que a terra vem sofrendo, é necessário a conscientização dos seres humanos acerca da importância de uma relação sustentável com a natureza, cabendo, neste caso, à escola atuar como um importante espaço de aprendizagem e conscientização.

A socialização entre as crianças propicia um compartilhamento de elementos da cultura. Esses elementos são manifestados de diversas formas, sejam por representações, símbolos ou imagens. Portanto, carregado de significações e características da realidade. Sendo a infância um momento de intensa assimilação dessas representações, as brincadeiras e brinquedos se destacam como importantes ferramentas de difusão de concepções e significações culturais da sociedade em que a criança está inserida. Essa realidade apresentada por essas atividades está diretamente ligada ao seu convívio e cotidiano, consequentemente, o interesse despertado nos meninos e meninas irá se diferenciar considerando as práticas realizadas nessas comunidades (BROUGÈRE,1997).

Assim como o modo de viver dessas comunidades se diferencia das que vivem na área urbana, as brincadeiras e brinquedos também apresentam um conjunto de peculiaridades, o que nos remete ao passado desses povos indígenas. Além do caráter lúdico e de socialização, as brincadeiras feitas eram intrinsecamente ligadas aos objetivos de ensinar e aconselhar os imaturos acerca de suas responsabilidades futuras. Portanto, muitas dessas brincadeiras eram passadas pelo exemplo dos mais velhos e por meio da imitação, servindo para observar e estimular as aptidões individuais, desenvolvendo-se na interação com outras crianças. A medida de exemplo, meninos indígenas que se destacavam no uso e manuseio de arcos, flechas e lanças passavam a desempenhar a função de caçar na comunidade. Os que tinham mais facilidade na confecção de brinquedos eram direcionados a se tornar os futuros artesãos da aldeia. Fazendo da brincadeira um mecanismo de estimulação para as práticas sociais.

Os brinquedos indígenas, objetos confeccionados pelas crianças e por seus pais, representam uma importante manifestação dessa cultura, sendo expressos nele elementos da vida cotidiana (FERNANDES, 1975). Importante fonte de estudo para conhecer sobre os modos de vivência desses povos tradicionais. Normalmente, esses brinquedos eram miniaturas de ferramentas e utensílios do dia a dia. As meninas costumavam brincar de bonecas feitos de sabugo de milho, de madeira, pintadas com tinta de jenipapo e urucum (frutos nativos da região), faziam também potes e 
jarros de barro remetendo ao trabalho praticado pelas mulheres nas aldeias, o de cuidarem das crianças e serem responsáveis pela casa, pela comida.

Segundo a índia Tupinambá Iacitara (nome fictício), moradora da aldeia Tucum e professora da EEITO, muitos desses costumes foram vivenciados por ela e seus irmãos. Era comum os meninos brincarem de gangorra feita de cipó e madeira, cavalo de pau feita por vara e corda, confeccionavam maracás de cabaça utilizados como chocalhos, pequenos arcos e cocares. Aproveitavam o rio para competições, trabalhando a habilidade de cada um, vencendo quem mergulhava por mais tempo, atravessando as águas do rio inúmeras vezes para testar quem seria o melhor nadador. A professora Iracema (nome fictício), educadora da creche e pré-escola Katuana, também se recorda dessas brincadeiras durante sua infância, acrescentando o uso de cipó para confecção de bambolês, e a utilização dos mesmo cipós em brincadeiras com corda. A educadora também se lembra de demais jogos como, as corridas com o maracá e arremesso de lança. As músicas de roda, uma importante ferramenta de transmissão de conhecimentos e valores, e comum nas brincadeiras indígenas nos dias de lua cheia, eram ensinadas pelos mais velhos que costumavam falar sobre a importância de ter cuidado com a natureza e os animais para que desde cedo esses jovens aprendessem sobre o respeito com a natureza, característica da crença Tupinambá na existência dos guardiões das florestas. Provocando um sentimento de proteção e harmonia para com o meio ambiente. Segundo o folclorista Câmara Cascudo (1972):

essas brincadeiras transmitidas oralmente, abandonadas em cada geração e reerguida pela outra, numa sucessão ininterrupta de movimento e de canto.

Reconhecendo a importância da transmissão das atividades lúdicas como também transmissão de tradição e afirmação de identidade cultural, são realizados nas aldeias e escolas indígenas oficinas procurando resgatar essas atividades como forma de valorizar os costumes indígenas. Professores incentivam os alunos a confeccionarem alguns desses objetos procurando aproximá-los a essa cultura que tem tanto a ensinar. 


\section{Conclusão}

Inevitavelmente, os limites de nossas fontes e de nossa metodologia impedem-nos de traçar uma análise com maior abrangência frente ao processo de organização societária Tupinambá de ontem e hoje. Todavia, ao examinarmos a educação e o universo das brincadeiras como importantes dispositivos regulatórios da ordem societária deste povo, revisando bibliografias e cruzando informações resultantes de observações participantes e entrevistas, conseguimos compreender a tamanha importância que os dispositivos supracitados possuem dentro de uma sociedade indígena contemporânea e de cinco séculos atrás, visto que tais ferramentas desempenham um papel norteador e delineador das relações socioambientais, abarcando também, processos vitais para a existência de um grupo com estes preceitos, pois a preservação dos conhecimentos tradicionais e da herança cultural como um todo, está intrinsecamente atrelada às relações entre seus agentes sociais e os espaços naturais. Assim sendo, não podemos excluir de nossa delimitada perspectiva, a grande intervenção da modernidade e pós-modernidade no que diz respeito aos brinquedos industrializados, os quais seguem uma lógica racional para o mercado. Tais produtos em sua maioria, são cheios de representação e significações de uma determinada sociedade (BROUGÈRE, 1997). Por exemplo, as bonecas industrializadas na maioria das vezes feitas de plástico e que frequentemente seguem um padrão determinado, não abrangem a realidade da grande maioria das crianças brasileiras. Destarte a inserção desses brinquedos em diferentes comunidades, resulta na difusão de uma imagem idealizada, que influencia o imaginário dessas crianças.

Ao contrário desse quadro que visa principalmente o lucro, os brinquedos artesanais nas comunidades tradicionais proporcionam às crianças e seus pais um estímulo à criatividade, habilidades e principalmente à liberdade para a construção desses produtos segundo seus próprios traços culturais, e os materiais desejados encontrados na natureza ensejando, corriqueiramente, o contato com os espaços naturais.

Segundo Brougère: olhar para o brinquedo é se confrontar com o que se é ou, ao menos,
com a imagem do mundo e da cultura que se quer mostrar à criança.
brinquedo é um objeto que traz em si uma realidade cultural, uma
visão de mundo e de criança( 1992, p. 65).

Faz se necessário então, preservar esta maneira ímpar de se relacionar com a construção e utilização dos brinquedos reconhecendo esta prática como meio de salvaguardar a identidade cultural indígena, e fazer frente ao contínuo avanço dos brinquedos industrializados no contexto deste segmento social. 
Em virtude dos argumentos apresentados, precisamos pontuar de forma sucinta -visamos futuramente a análise deste tópico em uma pesquisa mais profunda - a relevante discussão sobre da função de um agente já conhecido neste processo, porém configurado com novas diretrizes pós Constituição de 1988, como por exemplo, a Resolução CNE 1999 que estabelece as diretrizes da educação escolar indígena, evidenciando o papel da Bem como, de maneira significativa esta outra perspectiva de construção do conhecimento no âmbito escolar que consegue manter a dinâmica social característica da educação horizontal entre seus agentes, compromissada com uma coexistência menos degradável entre sujeito e natureza. 


\section{Referências}

ALMEIDA, Maria Regina Celestino de. Metamorfoses indígenas: identidade e cultura nas aldeias coloniais do Rio de Janeiro. Rio de Janeiro: Arquivo Nacional, 2003.

BROUGÈRE, Gilles. Brinquedo e Cultura. 2 ed. São Paulo: Cortez, 1997.

CONFERÊNCIA NACIONAL DOS BISPOS DO BRASIL (CNBB). Por uma Terra sem Males. Fraternidade e Povos Indígenas: Texto-Base da Campanha da Fraternidade 2002. São Paulo: Salesiana, 2001.

CONSELHO NACIONAL DE EDUCAÇÃO (CNE). "Parecer no 03/99", de 10/11/1999. Disponível em http://portal.mec.gov.br/cne/arquivos/pdf/rceb03_99.pdf. Acesso em 06/09/2013.

FERNANDES, Florestan. "Notas sobre a educação na sociedade tupinambá". In: FERNANDES, F. A investigação etnológica no Brasil e outros ensaios. Petrópolis: Vozes, 1975, pp. 33-83.

LEITE, Serafim. História da Companhia de Jesus no Brasil: da Baía ao Nordeste: estabelecimentos e assuntos locais. Lisboa: Portugália; Rio de Janeiro: Civilização Brasileira, 1945. p. 216-226. (Tomo V.cap. X)

MARCIS, Teresinha. A “hecatombe de Olivença": construção e reconstrução da identidade étnica - 1904. 2004. Dissertação de mestrado em História Social - Universidade Federal da Bahia, 2004.

MONTEIRO, John. Negros da terra: índios e bandeirantes nas origens de São Paulo. São Paulo: Companhia das Letras, 1994.

MONTEIRO, John. Tupis, Tapuias e historiadores: Estudos de história indígena e do indigenismo. Tese (Livre Docência). Campinas: UNICAMP, 2001.

THOMPSON, E. P. A formação da classe operária inglesa. Rio de Janeiro: Paz e Terra, 1987.

KISHIMOTO, Tizuko Morchida. Jogos Infantis: o jogo, a criança e a educação. 5 ed, Petrópoles, Rio de janeiro: Vozes, 1993. 